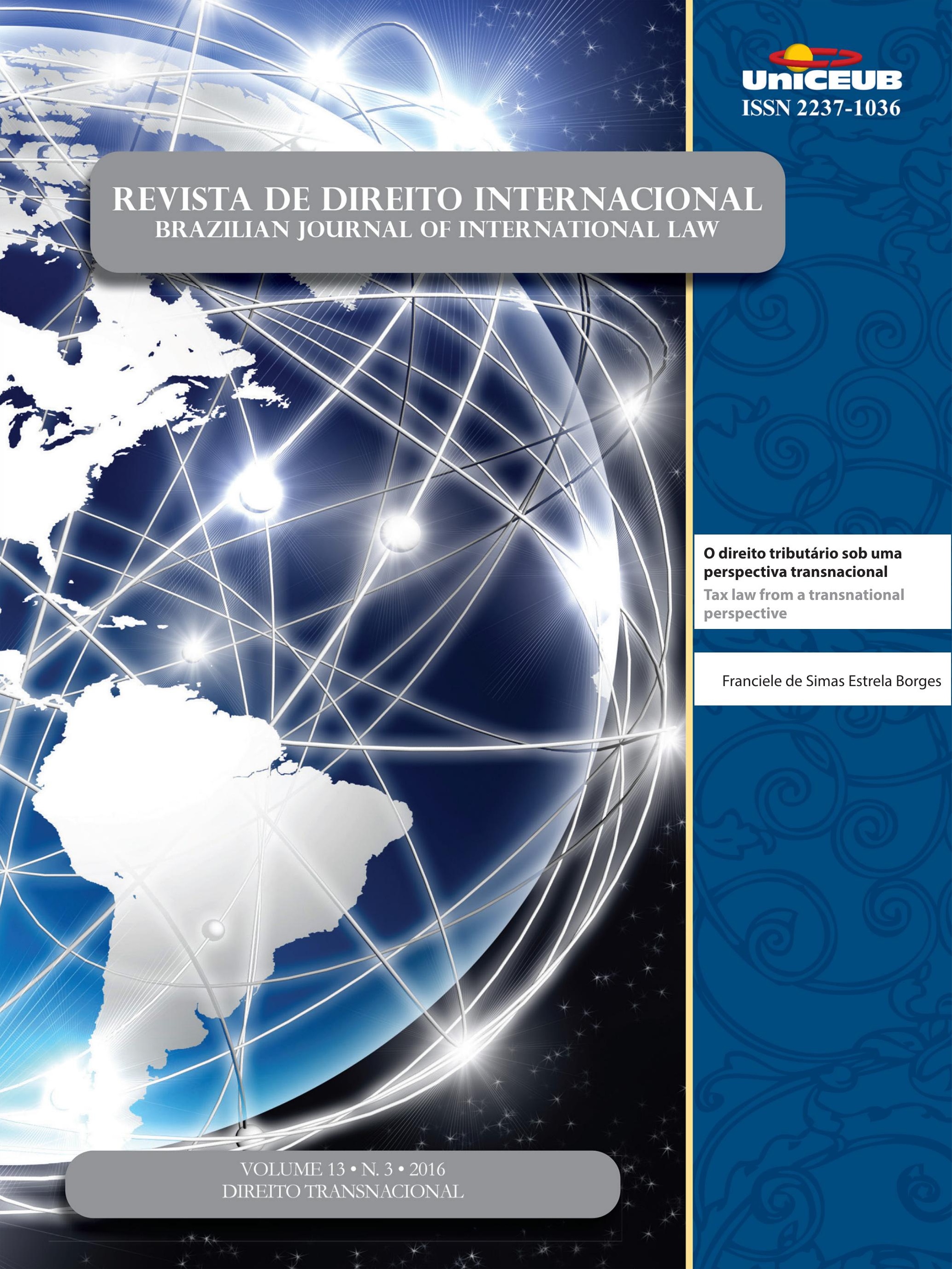


Crônicas da ATUALIdAde do direito internacional .................................................. 2

I. Dossiê Temático: Direito Transnacional .........................................................15

EDITORIAL: O Direito Transnacional - Circulação de normas e relações jurídicas transnacionais .......16 Priscila Pereira de Andrade

A emergênCia do direito transnacional ambiental .............................................18 Priscila Pereira de Andrade

Desafíos y RESPUESTAS TRANSNACIONALES FRENTE A LOS CRÍMENES AMBIENTALES ...............30 Rosmerlin Estupiñan-Silva

DiREITO TRANSNACIONAL E MUdANÇAS CLIMÁTICAS .50 Géraud de Lassus Saint-Geniès

Especies en movimiento: la Convención sobre el Comercio Internacional de Especies Amenazadas de Fauna y Flora Silvestres como espacio de “Encuentro” de discursos, ACTORES Y ESTRATEGIAS EN EL DERECHO AMBIENTAL TRASNACIONAL

María Valeria Berros e Dabel Leandro Franco

El carácter transnacional del Sistema comunitario de ECogestion « Eco-ManageMENT AND Audit SCHEME » (EMAS) DENTRo de LA UE y MÁs ALlÁ DE SUS Fronteras ......72 Adélie Pomade

O CONCEITO DE CONDUTA EMPRESARIAL RESPONSÁVEL À LUZ DOS ORDENAMENTOS JURÍDICOS BRASILEIRO, INTERNACIONAL E TRANSNACIONAL

Gabriel Webber Ziero

ARBITRAGEM NO DIREITO TRIBUTÁRIO INTERNACIONAL E NO DIREITO INTERNACIONAL DOS INVESTIMENTOS: UMA MANIFESTAÇÃO DO DIREITO TRANSNACIONAL

Vivian Daniele Rocha Gabriel 
O DIREITO TRIBUTÁRIO SOB UMA PERSPECTIVA TRANSNACIONAL

Franciele de Simas Estrela Borges

As Características do Direito Transnacional como Metodologia: Análise sob o enfoQue dos Aspectos Processuais da Arbitragem 126

Flávia Foz Mange

O DIREITO TRANSNACIONAL (“GLOBAL LAW") E A CRISE DE PARADIGMA DO ESTADO-CENTRISMO: É POSSÍVEL CONCEBER UMA ORDEM JURÍDICA TRANSNACIONAL? ...................................... 146

Luiza Nogueira Barbosa e Valesca Raizer Borges Moschen

TransPorte AÉREO E DIREITO TRANSNACIONAL: DA CONVERGÊNCIA À UNIFORMIDADE 160 Mickael R. Viglino

Outros Artigos. 175

O Fundo Monetário Internacional e a proteção dos direitos humanos: uma análise DO PROGRAMA DE CRESCIMENTO E REDUÇÃO DA POBREZA NO HAITI 177

Pablo Henrique Hubner de Lanna Costa e Carlos Alberto Simões de Tomaz

Um estranho no ninho? Padrões privados no Acordo de Barreiras Técnicas ao CoMÉRCIO DA OMC 192

Michelle Ratton Sanchez Badin e Marina Yoshimi Takitani

Os benefícios tributários do programa Inovar-Auto e os princípios da Nação Mais Favorecida e do Tratamento Nacional: uma análise dos argumentos dos Painéis atualmente em Curso contra o Brasil no Órgão de SoluÇão de Controvérsias da OMC . 211 Eric Moraes Castro e Silva

A ERA DA HUMANIDADE: REFLEXões PARA A HISTÓRIA DO DIREITO INTERNACIONAL 236 Henrique Weil Afonso

Precedentes vinculantes nos Estados Unidos da América e no direito brasileiro: Um ESTUDO COMPARADO 264

Patrícia Perrone Campos Mello 
IL DIRITTO AMBIENTALE SECONDO L'OTTICA DEL DIRITTO COSTITUZIONALE POSITIVO E LA RESPONSABILITÀ PER DANNI ALL'AMBIENTE NEL DIRITTO COMUNITARIO: LO STATO DELL'ARTE DEL DIRITTO AMBIENTALE COSTITUZIONALE E COMUNITARIO 287

Elcio Nacur Rezende

DA DESCONSIDERAÇÃo DA PERSONALIDADE JURÍDICA NAS RELAÇÕES CONSUMEIRISTAS BRASILEIRAS: ANÁLISE À LUZ DAS TEORIAS CLÁSSICAS

Daniel Amin Ferraz e Marcus Vinicius Silveira de Sá

ANALYSIS OF ADVANTAGES AND DISADVANTAGES OF FORUMS PRESCRIBED UNDER THE UNCLOS AND STATE PRACTICE: THE WAY AHEAD FOR INDIA ......................................................319

Vinai Kumar Singh

Do governo POR LEIS À governanÇA POR NúMERos: breve anÁlise do Trade in SERVICE AgreEMENT (TISA) ...............................................................................338 Jânia Maria Lopes Saldanha, Rafaela da Cruz Mello e Têmis Limberger

As DIRETIVAS EUROPEIAS COMO NORMA REGULADORA DO DIREITO ADMINISTRATIVO GLOBAL ..356 Alice Rocha da Silva e Ruth Maria Pereira dos Santos

O desenVolvimento da POlítica AGRícola COMUM dA UNião EUROPEIA 375 Tatiana de A. F. R. Cardoso Squeff

A imunidade de Jurisdição das organizaÇões internacionais FaCE AO Direito de aCESSO À JUSTIÇA 391

Fernanda Araújo Kallás e Caetano

O DIREITO INTERNACIONAL ENTRE O DEVER ÉTICO E A AÇÃo POLÍ́TICA: OS FUNDAMENTOS DE UM DEVER DE COOPERAÇÃO INTERNACIONAL NA FILOSOFIA POLÍTICA DE IMMANUEL KANT .405 Ademar Junior Pozzatti

EXTENSÃo E FRAGMENTAÇÃo NO CONTEXTO DA JURISDIÇÃO PENAL INTERNACIONAL .423 Marcus Vinícius Xavier de Oliveira

A DEFINiÇÃo JURÍdiCA DA "COMUNIDADE" .444 Nitish Monebhurrun, Michelle Lucas Cardoso Balbino, Fernanda Castelo Branco Araujo, Othon Pantoja, Míara Bogo Bruno e Cândida Dettenborn Nóbrega 
Comparative Study on Chinese Local Legislation of Science and Technology ProGRESS

LI Xiaoming e LI Yihan

O CONTROLE PENAL DO TRÁFICO DE PESSOAS: CONSTRUÇÃO JURÍDICA, INTERAÇÕES ORGANIZACIONAIS E COOPERAÇÃO INTERNACIONAL

Bruno Amaral Machado e Priscilla Brito Silva Vieira

Desativismo judicial: a extradição Battisti no Supremo Tribunal Federal .505 Francisco Rezek e Israel Paulino

A decisão norte-americana do Caso Myriad: novos paradigmas para a Proteção patenTÁRIA DO CÓDIGO GENÉTICO HUMANO E BIOTECNOLOGIA 514 José Carlos Vaz e Dias e Clarisse De La Cerda 


\title{
O direito tributário sob uma perspectiva transnacional*
}

\section{Tax law from a transnational perspective}

\author{
Franciele de Simas Estrela Borges**
}

\begin{abstract}
Resumo
O presente artigo versa sobre o fenômeno da transnacionalização do direito, com foco no direito tributário. Com base em uma análise de situações transnacionais que evolvem os sistemas tributários nacionais, os tratados internacionais, as normas modelos emanadas das organizações internacionais e os planejamentos tributários elaborados pelas empresas transnacionais, instaura-se uma reflexão sobre a necessidade de se pensar o direito tributário sob uma perspectiva transnacional.
\end{abstract}

Palavras chaves: direito transnacional, direito tributário, empresa transnacional, ordem jurídica transnacional tributária.

\section{Abstract}

This article deals with the phenomenon of transnationalisation of law, with a focus on tax law. Based on an analysis of transnational situations that involve national tax systems, international treaties, model norms emanating from international organizations and tax planning developed by transnational corporations, the paper proposes an analysis of the need to consider tax law under a transnational perspective.

Keywords: transnational law, tax law, transnational companies, transnational legal order

\section{INTRODUÇÃo}

São inegáveis os efeitos que o fenômeno da globalização surtiu no direito, levando a uma maior discussão acerca do direito transnacional nos últimos anos. A grande expansão do comércio e das operações transnacionais associada à revolução tecnológica da informática e das telecomunicações possibilitou novos arranjos de ordem tributária, levando a debates que envolvem tanto a questão da soberania dos Estados, o papel dos organismos internacionais, como o impacto e a natureza jurídica dos planejamentos tributários elaborados pelas empresas transnacionais ${ }^{1}$.

1 Por empresas transnacionais adotaremos no presente estudo a definição estabelecida pela Conferência das Nações Unidas para o Comércio e o Desenvolvimento - UNCTAD, qual seja: $A T N C$ is an enterprise, which is irrespective of its country of origin and its ownership, including 
Diante da diversidade das normas em matéria de tributação da renda da pessoa jurídica e os inúmeros tratados internacionais firmados entre os países para evitar a bitributação, as empresas transnacionais encontram maior liberdade para, de uma maneira inteiramente legal, elaborar suas próprias regras de arrecadação tributária de modo a obter uma maior otimização possível dos custos.

A incessante busca pelos ganhos de produtividade, o dinamismo das sociedades transnacionais e a diminuição das fronteiras transnacionais despertam "questões concretas de como os fiscos locais irão se adaptar e sobre o risco de que um acirramento da competição tributária entre países possa levar os governos a se tornarem incapazes de atender as legítimas demandas de seus cidadãos por serviços públicos" ${ }^{2}$.

Partindo de uma análise sobre o modo como as empresas transnacionais e os Estados atuam em defesa dos seus interesses em matéria tributária (parte 1), o presente artigo tem por objetivo fazer uma reflexão sobre pluralismo jurídico no plano tributário internacional e o surgimento de uma ordem jurídico tributária transnacional (parte 2).

\section{OtıMIZAÇão, harmonização E CONCORRÊNCIA FISCAL: GUERRA DE INTERESSES TRIBUTÁRIOS}

Para melhor entendermos a problemática da transnacionalização no direito tributário, necessário se faz uma breve análise de situações transnacionais que envolvem normas internas e internacionais tributárias, bem como as regras de planejamento tributário, criadas pelas sociedades transnacionais. Neste estudo, o foco

private, public or mixed, which comprises entities located in two or more countries which are linked, by ownership or otherwise, such that one or more of them may be able to exercise significant influence over the activities of others and, in particular, to share knowledge, resources and responsibilities with the others. TNCs operate under a system of decision making which permits coherent policies and a common strategy through one or more decision-making centres. This definition does not regard the legal form and fields of activity of these entities. Ver: UNCTAD. Structure of TNCs. Disponível em: <http:// unctad.org/en/Pages/DIAE/Investment $\% 20$ and $\% 20$ Enterprise/ Structure-of-TNCs.aspx>. Acesso em: 20/08/2015.

2 MOTTA, João Ricardo Santos Torres. FONTANIVE, Vicente Marcos. A tributação em face da globalização. Disponível em: <http://bd.camara.leg.br/bd/handle/bdcamara/2242>. Acesso em: 10/08/215. será direcionado para as empresas do ramo digital, pela grande polêmica que as técnicas de otimização fiscal desenvolvidas por essas empresas têm suscitado nos últimos anos ${ }^{3}$.

Atualmente, os diferentes tratamentos tributários nos sistemas nacionais e o grande número de tratados internacionais existentes em matéria tributária possibilitam às sociedades transnacionais uma grande liberdade de transferir os benefícios econômicos adquiridos no mundo inteiro em função da situação fiscal ofertada por cada país. Pela capacidade de orientar as suas operações em diversos pontos do mundo em busca de uma minimização dos custos, as empresas transnacionais conseguem se isentar dos impostos dos países onde exercem, efetivamente, suas atividades e aproveitar as baixas cargas tributárias de determinados países, de forma inteiramente legal ${ }^{4}$.

Isto porque a forma de tributação das operações transnacionais e dos rendimentos das pessoas jurídicas diferencia-se de país para país, de acordo com o interesse interno de cada um. Se, de um lado, alguns países defendem, veementemente, a ideia de uma harmonização das normas tributárias, com alíquotas idênticas ou semelhantes, como, por exemplo, a França e a Alemanha, de outro, há os que preferem um sistema de concorrência tributária internacional, como é o caso da Irlanda e Luxemburgo.

Consequentemente, as sociedades transnacionais levam em conta as diversas opções fiscais e se organizam por meio de planejamentos tributários, que podem ser considerados como "procedimento de interpretação do sistema de normas, visando à criação de um modelo de ação para o contribuinte, caracterizado pela otimização

3 "A economia digital caracteriza-se por basear-se como nenhuma outra nos ativos intangíveis, pelo uso massivo de dados (particularmente dados pessoais), pela utilização generalizada de modelos de negócios multilaterais, capturando valor das externalidades geradas por produtos gratuitos, e pela dificuldade em determinar a jurisdição na qual o valor é criado. Isto gera questões fundamentais, tais como de que forma as empresas na economia digital acrescentam valor e geram os seus lucros e de que modo a economia digital se relaciona com os conceitos de origem e residência, ou com a caracterização dos rendimentos para fins tributários". Ver: OCDE. Plano de ação para o combate à érosão da base tributária e à transferência de lucros. Disponível em: > http://www.oecd-ilibrary.org/docserver/ download $/ 231333$ ue.pdf ?expires $=1445816433 \&$ id=id\&accname $=$ guest $\&$ checksum $=604583$ FBF5564E9C94E5542018049C5F $>$. Acesso em: 15/05/2015.

4 BAPTISTA, Luiz Olavo. Empresa transnacional e direito. São Paulo: Revista dos tribunais: 1987, p. 25. 
da conduta como forma de economia tributária, num agir voltado imediatamente para o sucesso" ${ }^{5}$. No plano internacional, o planejamento tributário deve levar em conta a análise das normas tributárias de todos os países envolvidos e dos tratados internacionais concernentes.

Como forma de atrair novos investimentos, alguns países vêm criando medidas de incentivo fiscal, estabelecendo alíquotas tributárias reduzidas que, associadas aos tratados internacionais de isenção tributária, propiciam vantajosos cenários fiscais a algumas instituições. Assim, as empresas criam filiais em diversos países para gerenciar suas atividades e, ao concentrar os lucros nos estabelecimentos localizados nos países com tributação favorecida, a tributação global do grupo é minimizada.

Exemplo disso são as medidas de incentivos fiscais criadas pelo governo irlandês que, em troca de criação de emprego e outros benefícios oriundos da instalação das empresas em seu território, favorecem as empresas com uma reduzida alíquota de imposto sobre a renda de $12,5 \%$, o que é altamente atrativo se comparado às alíquotas da Alemanha (quase 30\%) e da França (33,33\%). Para ser ainda mais atrativa, a Irlanda, também, reduziu os impostos sobre a propriedade intelectual. Outros países como a Grande Bretanha, Luxemburgo, Países Baixos e Espanha instituíram o regime de "patent box", incentivo fiscal que permite que as empresas exploradoras de patentes no Reino Unido possam deduzir, de forma significativa, os impostos incidentes sobre os seus produtos patenteados ${ }^{6}$.

Tais medidas favorecem a criação de técnicas de otimização fiscal que permitem as empresas, principalmente do ramo digital, pagar $2 \%$ (dois por cento) de imposto sobre a renda. O exemplo mais conhecido é a técnica conhecida como "sanduíche irlandês", utilizada por grandes empresas da tecnologia da informação, dispositivo fiscal que possibilita aos grandes grupos internacionais reduzir, significativamente, sua contribuição tributária. Com uma filial na Irlanda e royalties que transitam nos Países Baixos, antes de serem enviados aos paraísos fiscais, as empresas se submetem a um imposto de renda quase inexistente, isentando-se do pagamento de impostos nos países onde, efetivamente, exercem

5 TÔRRES, Heleno Taveira. Direito tributário internacional: planejamento tributário e operações transnacionais. São Paulo: Revista dos Tribunais, 2001, p. 36.

6 Reino Unido. Corporation tax: the patente box. Disponível em: $<$ https://www.gov.uk/guidance/corporation-tax-the-patent-box $>$. Acesso em: 15/05/2015. suas atividades 7

Sob pressão dos Estados Unidos e da União Europeia, o governo irlandês adotou medidas para pôr fim ao regime de duplo incentivo fiscal ${ }^{8}$. Todavia, tal atitude não será suficiente para minimizar as práticas de otimização fiscal adotadas pelas empresas, pois outros países como Luxemburgo, os Países Baixos e a Suíça, também, oferecem regimes favoráveis às transnacionais. Além do mais, as empresas, tendo em vista a dinamicidade que lhes é peculiar, já vêm se reestruturando em busca de novas possibilidades em matéria de otimização fiscal ${ }^{9}$.

Diante desse cenário, a Organização para a Cooperação e o Desenvolvimento Econômico - OCDE, a Organização das Nações Unidas - ONU e a União Europeia estão, cada vez mais, interessadas em combater tais práticas, pois entendem que se trata de evidente elisão fiscal. A OCDE elaborou um plano de ação para reduzir as estratégias fiscais que permitem as transnacionais de evitar a arrecadação da tributação em seu país de origem, sob o argumento de que as empresas devem recolher seus impostos nos locais onde são geradas suas riquezas. O plano de ação visa, primordialmente, "estabelecer a coerência internacional em relação ao imposto sobre a pessoa jurídica" e assegurar a transparência nos planejamentos e transações em matéria tributária por

7 Haja vista o tratado internacional estabelecido entre a Irlanda e os Países Baixos, que isenta o pagamento de imposto sobre a propriedade intelectual (patente, direitos autorais etc), as empresas criam uma filial irlandesa para gerenciar toda a receita dos produtos vendidos na Europa, Ásia e Oriente Médio e transferem as receitas a uma holding estabelecida nos Países Baixos. Livre de imposto, a receita é novamente transferida para a Irlanda, desta vez para uma outra holding instalada no país, mas com domicílio fiscal em países considerados como paraísos fiscais (Ilhas Virgens Britânicas, Ilhas Bermudas, etc). Assim, as empresas fazem transitar esses royalties pelos Países Baixos antes de enviá-los aos paraísos fiscais, uma vez que o país exonera os benefícios que saem de seu território em direção a estes países. Essa transição dos fundos entre duas sociedade para evitar o pagamento de impostos é conhecida como "sanduíche holandês". Neste sentido, ver: COLLET, Martin. Quelle fiscalité pour les entreprises transnationales. In: Séminaire 2013-2014 - Actualité du droit de l'entreprise. Paris: College de France, 2014. Disponível em: $<$ http:/ / www.college-de-france.fr/site/alain-supiot/seminar-201406-12-16h00.htm>. Acesso em: 27/08/2015.

8 A supressão do mecanismo teve fim em 01 de janeiro de 2015 para as novas empresas, com um regime transitório até 2020 para as empresas existentes.

9 Algumas empresas já anunciaram uma modificação em sua estrutura, com instalação de suas sedes em locais que oferecem benefícios fiscais. Neste sentido, veja-se como exemplo a reestruturação da Google com a criação da empresa "Alphabet”, a qual está instalada em Delaware, estado americano que oferece consideráveis benefícios fiscais às empresas que lá se instalam. 
meio de um amplo acesso às informações concernentes às empresas, para fins de identificar possíveis planejamentos tributários agressivos ${ }^{10}$.

Outro objetivo é reunir todas as regras tributárias internacionais em uma única convecção internacional, assinada pelo máximo de Estados, que se imporá às legislações nacionais, criando, assim, uma harmonização tributária no plano internacional ${ }^{11}$. Uma unificação das normas tributárias impediria que as empresas viessem a tirar proveito do tratamento fiscal diferenciado entre os países, o que diminuiria as transferências internacionais de capital e estabeleceria uma tributação de acordo com o lucro real das empresas, gerando um maior ingresso de recursos nos cofres públicos. Ademais, os contribuintes se submeteriam a taxas idênticas ou semelhantes, independentemente de seu domicílio fiscal, o que eliminando a necessidade de exílio fiscal em busca de uma tributação mais vantajosa e propiciaria uma concentração destas empresas em seus países de origem ${ }^{12}$.

Neste sentido, parte da doutrina defende que a aplicação de regras fiscais mais próximas à realidade econômica contribuiria na equidade e na transparência fiscal internacional e criaria condições de concorrência fiscais mais igualitárias, permitindo uma justa contribuição no financiamento dos serviços públicos fornecido pelos países onde as empresas exercem suas atividades ${ }^{13}$.

Sob outro ponto de vista, há que se considerar que uma saudável competição tributária internacional é necessária para uma melhor distribuição da arrecadação entre os países. Isto porque, uma harmonização tributária pode gerar uma maior concentração da arrecadação tributária em alguns países desenvolvidos, mais precisamente nos países de origem das empresas transnacionais ${ }^{14}$.

Os defensores da concorrência fiscal internacional ${ }^{15}$

10 OCDE. Plano de ação... op cit.

11 Uma convenção fiscal multilateral única seria destinada a substituir os mais de 3 mil tratados bilaterais.

12 PICCIOTTO, Sol. Towards unitary taxation of transnational corporations. Disponível em: <http://www.taxjustice.net/cms/ upload/pdf/Towards_Unitary_Taxation_1-1.pdf $>$. Acesso em: $23 / 08 / 2015$.

13 Idem.

14 PERROULAZ, Gérard. Firmes transnationales : instruments du développement ou instruments de pouvoir?. In: Annuaire suisse de politique de développement. Disponível em: < http://aspd.revues.org/1287>. Acesso em: 10/08/2015.

15 Neste sentido, ver: ALTSHULER. Rosanne; GOOSDPEED, Timothy J. Follow the leaders? evidence on European and US tax Competition. Disponível em: <http://econ.hunter.cuny.edu/wpcontent/uploads/2013/10/altshuler_goodspeed_dec063.pdf>. afirmam que ela é um importante instrumento para implementação de uma política fiscal pro-mercado, atraindo capitais e melhorando o desempenho econômico dos países. Ao revés, uma harmonização fiscal significaria alíquotas tributárias mais elevadas e discriminatórias, dificultando uma eficiente alocação de capital e trabalho e reduzindo o desempenho econômico global ${ }^{16}$.

Evidentemente que os países onde estão localizadas as empresas de alta lucratividade e que possuem altas cargas tributárias não veem como a melhor opção o estabelecimento de incentivos fiscais, preferindo a promoção de uma harmonização fiscal como meio de inibir a fuga de capital e de empregos em direção dos países com regime tributário mais favorável. Por outro lado, há aqueles países que preferem se lançar em uma concorrência fiscal, adotando medidas para impulsionar a economia da nação por meio da redução da carga tributária.

Portanto, constata-se que a soberania dos Estados, para elaborar os regimes tributários nacionais de acordo com o interesse interno dos países ${ }^{17} \mathrm{e}$ a interação dos diversos regimes fiscais nacionais no plano internacional, leva a lacunas e atritos, o que possibilita que as empresas transnacionais transitem entre as diferentes legislações tributárias, de modo a poder escolher as alíquotas que lhes são mais benéficas e a criar seus próprios mecanismos de arrecadação tributária.

A partir desse cenário transnacional, entre sistemas tributários nacionais, tratados internacionais, normas modelos, recomendações emanadas das organizações internacionais e planejamentos tributários internacionais elaborados pelas empresas, que se passa a analisar a possível existência de uma ordem jurídica transnacional em matéria tributária.

Acesso em: 10/08/2015.

16 MITCHELL, Dan. Tax competition and fiscal reform: rewarding pro-growth tax policy. Disponível em: < http://object.cato.org/sites/ cato.org/files/pubs/papers/russiaconference/mitchell.pdf $>$. Acesso em: $12 / 08 / 2015$.

17 Ressalte-se que os Estados estão constantemente na busca de proteger os interesses nacionais, sendo soberanos para escolher as normas que lhes forem mais adequadas. Assim, não há como intervir na liberdade de um país no estabelecimento das normas tributárias que lhe seja mais conveniente. Por isso, no âmbito das organizações internacionais, as regras são impostas à unanimidade, o que impede a efetivação de uma harmonização tributária no plano internacional. 


\section{A tRANSNACIONALIZAÇÃO DO DIREITO TRIBUTÁRIO}

Os ordenamentos jurídicos nacionais são regulados de acordo com as prioridades e interesses internos de cada Estado, sendo eles soberanos para exercer, de forma absoluta, a jurisdição dentro do próprio território. Todavia, no plano internacional, a soberania estatal, muitas vezes, não se realiza em sua plenitude, tendo em vista a necessidade de adequação das normas tributárias à política externa de outros países. Por meio da ratificação de tratados internacionais ou da sujeição às normas emanadas das organizações internacionais, os Estados se submetem a uma relação de interdependência e solidariedade uns aos outros, trazendo implícita a noção de parcial renúncia ao poder soberano ${ }^{18}$.

Por outro lado, no Estado Contemporâneo, os recursos econômicos se tornaram meios de obtenção de poder $^{19}$, fazendo com que os Estados fiquem cada vez mais vulneráveis a atores não estatais, tais como as empresas transnacionais, cujo poderio econômico chega muitas vezes a superar a economia de muitos países ${ }^{20}$. O domínio das transnacionais sobre os recursos econômi$\cos$ e, ainda, suas habilidades gerenciais e tecnológicas exerce grande influência no processo socioeconômico de desenvolvimento de alguns países, principalmente dos países em desenvolvimento ${ }^{21}$.

Por se tornarem centros de poder, as transnacionais têm a capacidade de se autorregular e elaborar suas próprias regras de política externa, desde que, evidentemente, não estejam em desconformidade com as normas estatais $^{22}$. Com base em uma análise minuciosa dos sis-

18 GRECO, Marco Aurélio. Transações eletrônicas: aspectos Jurídicos. In: GRECO, Marco Aurélio. Internet e Direito. $2^{\mathrm{a}}$ ed., São Paulo: Dialética, 2000, p. 15.

19 BOBBIO, Norberto. Structure et fonction dans la théorie du droit de Kelsen. In: BOBBIO, Norberto. Essais de théorie du droit. trad. M. Guéret. Paris: LGDJ,1998, p. 222-225.

20 Constata-se que no ranking das 100 maiores entidades econômicas do mundo, 29 empresas transnacionais figuram entre as 51 entidades, 19 são Estados. Ver: WINTER, Luis Alexandre Carta. Empresa transnacional como fato de desenvolvimento e integração regional para América Latina. Disponível em: <http:// www.publicadireito.com.br/conpedi/manaus/arquivos/anais/salvador/luis_alexandre_carta_winter.pdf $>$. Acesso em 10/08/2015.

21 OLIVEIRA, Anderson Nogueira; MAURO, Victor Silva. Empresas transnacionais e os direitos humanos. Disponível em: <http://www.publicadireito.com.br/ artigos $/$ ?cod=6e28943943dbed3c $>$. Acesso em: 18/08/2015.

22 MELLO, Celso D. de Albuquerque. Direito internacional econômico. Rio de Janeiro: Renovar, 2003 p. 109. temas tributários nacionais, dos tratados internacionais e das normas modelos emanadas pelas organizações internacionais, as empresas se planejam a fim de obter uma maior otimização tributária possível, criando, por assim dizer, seu próprio sistema tributário. Tal fenômeno leva alguns doutrinadores a classificá-las como uma "autoridade privada", capaz de fazer face às autoridades estatais por meio de uma "diplomacia triangular" 23.

Essa fragmentação da soberania Estatal acarreta o aparecimento de um pluralismo jurídico, a partir de uma flexibilização e diversificação da produção normativa, com novas fontes e modos de regulação do direito, inclusive com a implementação de mecanismos de regulação alternativa não estatal ${ }^{24}$. Por tais motivos, o direito tributário não pode se restringir apenas aos sistemas tributários nacionais e aos estudos das relações dos próprios Estados e os tratados realizados entre eles, mas deve, sob um ponto de vista global, levar em consideração os arranjos tributários criados pelas próprias empresas transnacionais. Essa interação normativa abre caminho para uma reflexão sobre uma possível transnacionalização do direito tributário.

Por direito transnacional entende-se "um conjunto de normas que regula atos ou fatos que transcendem fronteiras nacionais, tanto do direito público quanto do privado, bem como outras normas que não se enquadram inteiramente nas categorias clássicas" ${ }^{25}$. JESSUP estabelece que a relação entre o direito internacional e o direito interno decorre de situações transnacionais que podem envolver pessoas físicas ou jurídicas, Estados, organizações de Estados, organizações internacionais e demais grupos que acabem por produzir um direito transnacional ${ }^{26}$.

23 'Borrowing from Stopford and Strange's triangular diplomacy model, private governance becomes a series of negotiations among public and private actors. Firms negotiate with other firms to advance and develop self-regulatory schemes. States negotiate with other states as to whether or not to grant firms such authority. Infuencing both sets of negotiations are the national patterns of private authority found in state-firm arrangements. The outcome is the state-firm negotiations that result in private authority. This is not a static outcome, but a dynamic one in that firms carry out private authority in the shadow of the state." Ver: COWLES, Maria Green. Private governance and e-commerce: triangular diplomacy and contested authority in the United States and European Union. Disponível em: <http://aei.pitt.edu/2851/1/102.pdf>. Acesso em: 24/10/2015.

24 MENEZES, Wagner. O direito internacional contemporâneo e a teoria da transnormatividade. Pensar, Fortaleza, v. 12, p. 134-144, mar. 2007.

25 JESSUP, Philip. Direito transnacional. Trad. Carlos Ramires Pinheiro da Silva. Rio de Janeiro: Fundo de Cultura, 1965. p. 87. 26 Idem. 
O direito transnacional tem por função "ajustar os casos e distribuir a jurisdição de maneira mais proveitosa para as necessidades e conveniências de todos os membros da comunidade internacional". Sob este ponto de vista, os problemas de proibição das leis não se resolvem por meio do princípio da territorialidade e soberania dos Estados, mas por meio de acordos internacionais, "maneira mais proveitosa para as necessidades e conveniências de todos os membros da comunidade internacional" 27.

É possível observar a existência do direito transnacional em diversas áreas, como a religiosa e esportiva, mas foi, no âmbito do comércio internacional, que ele foi mais estudado e teorizado, por meio da lex mercato$\mathrm{ria}^{28}$, verdadeiro direito transnacional comercial que surgiu a partir da análise das codificações e da elaboração de normas próprias criadas pelas sociedades econômicas.

A lex mercatoria se propagou em várias áreas de atuação como, por exemplo, na área petrolífera - lex petrolea -, marítima - lex marítima - e mesmo no âmbito do comércio eletrônico - lex electronica. Mesmo se do ponto de vista etimológico ou histórico ela se destina, apenas, ao direito comercial, a sua teoria vem exercendo forte influência em outros ramos do direito ${ }^{29}$.

Em matéria tributária, não é possível defender a existência de uma lex mercatoria propriamente dita como ordem jurídica independente, pela impossibilidade de descumprimento das normas nacionais no âmbito de jurisdição dos países. O que se verifica é o desenvolvimento de um corpo de regras elaborado pelas sociedades transnacionais com base na análise e na observância das normas tributárias de diversos sistemas jurídicos nacionais, tratados internacionais e normas modelos emanadas das organizações internacionais. Pode-se afirmar, portanto, que tais regras servem de lei às operações transnacionais, pois dão efetividade às normas tributárias estatais e regem o modo de contribuição das empresas transnacionais.

27 Ibid, p. 62.

28 Para um aprofundamento sobre a lex mercatoria, ver M. Berthold Goldman. Frontières du droit et lex mercatoria. In: Archives de philosophie du droit, Paris, T. IX, p. 177-192, 1964; LAGARDE, Paul. Approche critique de la lex mercatoria. In: Études offertes a Berthold Goldman. Le droit des relations économiques internationals. Paris: Litec, 1982.

29 LATTY, Franck. Droit transnational économique. In: DAILIER, Patrick. Droit de l'économie international. Paris: Pedone, 2004, p. 110-111.
É com base nessa perspectiva transnacional que se observa a necessidade de se pensar o direito tributário a partir de uma ordem jurídica transnacional tributária ${ }^{30}$, com várias formas de produção normativa, seja a partir do direito interno, do direito internacional e até mesmo de mecanismos de regulação alternativa não estatal, as quais atingem não somente os contribuintes, mas também os Estados soberanos e as relações que eles estabelecem entre eles.

Em suma, existe hoje, como uma realidade jurídica irrefutável, um processo de transnacionalização do direito tributário, impossível de ser ignorado. Portanto, não se pode mais conceber o direito como instrumento de organização da força monopolizada pelo Estado, como apregoava Hans Kelsen, pois não há mais como negar que os recursos econômicos propiciaram às autoridades privadas a obtenção de poder, levando-as a exercer forte influência sobre a produção normativa tributária e o relacionamento entre os países.

Conclui-se, portanto, que, no plano internacional, uma evolução do direito tributário, somente, seria possível com base em uma perspectiva transnacional do direito, levando-se em consideração a interação entre as normas de direito interno, de direito internacional e as normas particulares que regulam e dão efetividade à arrecadação tributária das sociedades transnacionais.

\section{Considerações finais}

Não há como se pretender desconsiderar os efeitos que a globalização vem surtindo no direito tributário nos últimos anos. Os recursos econômicos propiciam às empresas transnacionais a obtenção de poder, tornando-as verdadeiras instituições capazes de reger as normas tributárias da maneira que lhes for mais vantajosa no cenário internacional.

Contemporaneamente, um estudo global do direito tributário pressupõe não apenas a análise dos sistemas tributários nacionais, dos tratados internacionais e das

30 Evidentemente, pensar o direito tributário como um direito transnacional dependeria da própria concepção de ordem jurídica que, para a doutrina moderna, se relaciona com a existência de uma instituição. E, nesse aspecto, alguns doutrinadores consideram a societas mercatorum como uma verdadeira instituição, haja vista o poderio econômico e a influência que exercem sobre a soberania dos Estados. Ver: Ibid, p. 118. 
normas e diretrizes emanadas das organizações internacionais, mas também do planejamento tributário internacional elaborado pelas empresas transnacionais. Sob esse prisma, não há como ignorar o fenômeno da transnacionalização do direito e a pluralização das normas em matéria tributária, sendo plausível defender o surgimento de uma ordem jurídico tributária transnacional.

Pensar no direito tributário com base em uma perspectiva transnacional é imprescindível para que se possa chegar, de maneira mais proveitosa possível, à solução dos impasses de natureza tributária internacional, oriundos da diversidade de interesses das instituições que integram esse sistema jurídico tão complexo e multifacetário.

\section{ReferênCias Bibliográficas}

ALTSHULER. Rosanne; GOOSDPEED, Timothy J. Follow the leaders? evidence on European and US tax competition. Disponível em: < http://econ.hunter. cuny.edu/wp-content/uploads/2013/10/altshuler_goodspeed_dec063.pdf>. Acesso em: 10/08/2015.

BAPTISTA, Luiz Olavo. Empresa transnacional e direito. São Paulo: Revista dos tribunais, 1987.

BOBBIO, Norberto. Structure et fonction dans la théorie du droit de Kelsen. In: BOBBIO, Norberto. Essais de théorie $\boldsymbol{d u}$ droit. trad. M. Guéret. Paris: LGDJ, 1998.

COLLET, Martin. Quelle fiscalité pour les entreprises transnationales. In: Séminaire 2013-2014 - Actualité du droit de l'entreprise. Paris: College de France, 2014. Disponível em: <http://www.college-de-france.fr/site/alain-supiot/seminar-2014-06-12-16h00.htm>. Acesso em: 27/08/2015.

COWLES, Maria Green. Private governance and e-commerce: triangular diplomacy and contested authority in the United States and European Union. Disponível em: <http://aei. pitt.edu/2851/1/102.pdf>. Acesso em: 24/10/2015.

CRUZ, Paulo Márcio; BODNAR, Zenildo. A trasnacionalidade e a emergência do Estado e do direito transnacional. Revista Faculdade de Direito Sul de Minas, Pouso Alegre, v. 26, n. 1, p. 159-176, jan./jul. 2010.

GOLDMAN, Berthold. Frontières du droit et lex mercatoria. In: Archives de philosophie du droit. Paris, T. IX, p. $177-$ 192, 1964.
GRECO, Marco Aurélio. Transações eletrônicas: aspectos Jurídicos. In: GRECO, Marco Aurélio. Internet e Direito. $2^{a}$ ed. São Paulo: Dialética, 2000.

JESSUP, Philip. Direito transnacional. Trad. Carlos Ramires Pinheiro da Silva. Rio de Janeiro: Fundo de Cultura, 1965.

LAGARDE, Paul. Approche critique de la lex mercatoria. In: Études offertes a Berthold Goldman. Le droit des relations économiques internationales. Paris: Litec, 1982.

LATTY, Franck. Droit transnational économique. In: DAILIER, Patrick. Droit de l'économie international. Paris: Pedone, 2004.

MELLO, Celso D. de Albuquerque. Direito internacional econômico. Rio de Janeiro: Renovar, 2003.

MENEZES, Wagner. O direito internacional contemporâneo e a teoria da transnormatividade. Pensar, Fortaleza, v. 12, p. 134-144, mar. 2007.

MITCHELL, Dan. Tax competition and fiscal reform: rewarding pro-growth tax policy. Disponível em: <http://object.cato.org/sites/cato.org/files/pubs/ papers/russiaconference/mitchell.pdf $>$. Acesso em: 12/08/2015.

MOTTA, João Ricardo Santos Torres. FONTANIVE, Vicente Marcos. A tributação em face da globalização. Disponível em: <http://bd.camara.leg.br/bd/ handle/bdcamara/2242>. Acesso em: 10/08/215.

OCDE. Plano de ação para o combate à érosão da base tributária e à transferência de lucros. Disponível em: <http://www.oecd-ilibrary.org/docserver/download $/ 231333$ ue.pdf?expires $=1445816433 \&$ id $=$ id\&accname $=$ guest $\&$ checksum $=604583$ FBF5564E9 C94E5542018049C5F>. Acesso em: 15/05/2015.

OLIVEIRA, Anderson Nogueira. MAURO, Victor Silva. Empresas transnacionais e os direitos humanos. Disponível em: <http://www.publicadireito.com. br/artigos/?cod=6e28943943dbed3c $>$. Acesso em: 18/08/2015.

PERROULAZ, Gérard. Firmes transnationales : instruments du développement ou instruments de pouvoir ?. In: Annuaire suisse de politique de développement. Disponível em: <http://aspd.revues.org/1287>. Acesso em: 10/08/2015.

PICCIOTTO, Sol. Towards unitary taxation of transnational corporations. Disponível em: < http:/ / www.taxju- 
stice.net/cms/upload/pdf/Towards_Unitary_Taxation_1-1.pdf>. Acesso em: 23/08/2015.

TÔRRES, Heleno Taveira. Direito tributário internacional: planejamento tributário e operações transnacionais. São Paulo: Revista dos Tribunais, 2001.

Princípios do direito tributário inter-

nacional. In: AMARAL, Antonio Carlos Rodrigues do.

Curso de direito tributário. São Paulo: Celso Bastos, 2002. p. 301-322.
UNCTAD. Structure of TNCs. Disponível em: < http:/ / unctad.org/en/Pages/DIAE/Investment $\% 20$ and $\% 20$ Enterprise/Structure-of-TNCs.aspx $>$. Acesso em: 20/08/2015.

WINTER, Luis Alexandre Carta. Empresa transnacional como fato de desenvolvimento e integração regional para América Latina. Disponível em: <http://www.publicadireito.com.br/conpedi/ manaus/arquivos/anais/salvador/luis_alexandre_carta_winter.pdf $>$. Acesso em 10/08/2015. 
Para publicar na Revista de Direito Internacional, acesse o endereço eletrônico www.rdi.uniceub.br ou www.brazilianjournal.org.

Observe as normas de publicação, para facilitar e agilizar o trabalho de edição. 